Goldschmidt 2021 Abstract

https://doi.org/10.7185/gold2021.6608

\section{Geochemical and isotopic data on hunting strategies of Paleolithic people in central Mongolia}

\author{
IRINA A. VISHNEVSKAYA ${ }^{1,2}$, ARINA $M$. \\ KHATSENOVICH $^{1}$, NATALIA G. SOLOSHENKO ${ }^{3}$, \\ TATIANA G. OKUNEVA ${ }^{3}$, DASHZEVEG BAZARGUR ${ }^{4}$, \\ ALEXEI KLEMENTIEV ${ }^{1}$, EVGENY P. RYBIN ${ }^{1}$ AND JOHN \\ W. OLSEN ${ }^{1,5}$ \\ ${ }^{1}$ Institute of Archaeology and Ethnography, SB RAS \\ ${ }^{2}$ Vernadsky Institute of Geochemistry and Analytical Chemistry, \\ RAS \\ ${ }^{3}$ Zavaritsky Institute of Geology and Geochemistry, UB RAS \\ ${ }^{4}$ Institute of Archaeology, MAS \\ ${ }^{5}$ School of Anthropology, University of Arizona \\ Presenting Author: vishnevskaia.i.a@gmail.com
}

Central Asia was a transit corridor for Paleolithic human populations created by several factors including climate change, shifts in habitats of prey species, and the exploitation of superior lithic raw material for knapping. The site of Moiltyn-am in the Orkhon Valley of central Mongolia contains Middle Paleolithic through Late Upper Paleolithic archaeological complexes reflecting sporadic occupational episodes. The most common faunal remains at sites in the Orkhon Valley include bovids, equids and Ovis. We analyzed bone samples with compositions different from that of the soil that effected them taphonomically. A dependency diagram (Fig. 1b) of $\mathrm{Sr}$ isotopic composition from its inverse content verifies these results. Analysis of REE composition revealed that bone samples from Moiltyn-am Layers 3 and 4 (ca. 36-38 ka) were fossilized without taphonomic impact from soil formation processes. The Strontium isotopic composition of those samples ranged from 0.70973 to 0.70983 , while the ${ }^{87} \mathrm{Sr} /{ }^{86} \mathrm{Sr}$ ratio of sediment samples from those same strata varied between 0.70938 and 0.70959. Samples were interpreted as local if they fell within a standard deviation of \pm 2 ( $\pm 2 \mathrm{SD}$ ). Statistical analysis reveals these ranges are similar, indicating that animals were procured within short distances from the Moiltyn-am site (Fig. 1).

This study was supported by the Russian Scientific Foundation, Project № 19-78-10112 and the Je Tsongkhapa Endowment for Central and Inner Asian Archaeology, University of Arizona.

Figure caption

Figure 1. (a) Comparison of REE compositions in bones and sediments from the Moiltyn-am site, Mongolia; (b) Dependency diagram of $\mathrm{Sr}$ inverse content from $\mathrm{Sr}$ isotopic composition; (c) Comparison of $\mathrm{Sr}$ isotopic composition $\pm 2 \mathrm{SD}$ in sediments (shaded grey) and bone samples. The juxtaposed areas indicate overlapping results for bone samples and sediments.
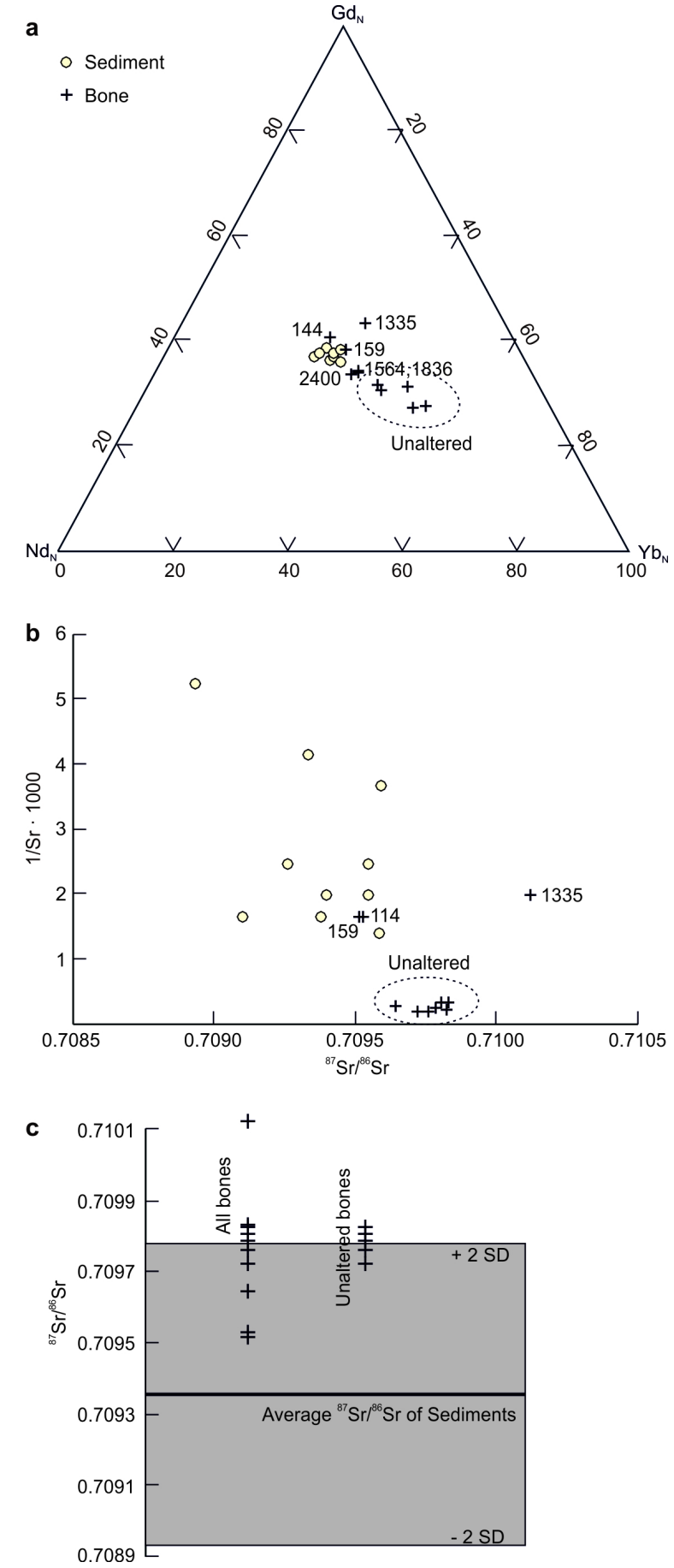